\title{
Unil
}

UNIL | Université de Lausanne

Unicentre

$\mathrm{CH}-1015$ Lausanne

http://serval.unil.ch

Year : 2019

\section{Decreasing body mass index is associated with cerebrospinal fluid markers of Alzheimer's pathology in MCI and mild dementia.}

\author{
Mathys Jules
}

Mathys Jules, 2019, Decreasing body mass index is associated with cerebrospinal fluid markers of Alzheimer's pathology in MCI and mild dementia.

Originally published at: Thesis, University of Lausanne

Posted at the University of Lausanne Open Archive http://serval.unil.ch

Document URN : urn:nbn:ch:serval-BIB_32DE3AA58C067

\section{Droits d'auteur}

L'Université de Lausanne attire expressément l'attention des utilisateurs sur le fait que tous les documents publiés dans l'Archive SERVAL sont protégés par le droit d'auteur, conformément à la loi fédérale sur le droit d'auteur et les droits voisins (LDA). A ce titre, il est indispensable d'obtenir le consentement préalable de l'auteur et/ou de l'éditeur avant toute utilisation d'une oeuvre ou d'une partie d'une oeuvre ne relevant pas d'une utilisation à des fins personnelles au sens de la LDA (art. 19, al. 1 lettre a). A défaut, tout contrevenant s'expose aux sanctions prévues par cette loi. Nous déclinons toute responsabilité en la matière.

\section{Copyright}

The University of Lausanne expressly draws the attention of users to the fact that all documents published in the SERVAL Archive are protected by copyright in accordance with federal law on copyright and similar rights (LDA). Accordingly it is indispensable to obtain prior consent from the author and/or publisher before any use of a work or part of a work for purposes other than personal use within the meaning of LDA (art. 19, para. 1 letter a). Failure to do so will expose offenders to the sanctions laid down by this law. We accept no liability in this respect. 


\section{Unil}

UNIL | Université de Lausanne

\section{Ecole doctorale}

UNIVERSITE DE LAUSANNE - FACULTE DE BIOLOGIE ET DE MEDECINE Département de Psychiatrie

Service Universitaire de Psychiatrie de la Personne Âgée

Titre de la thèse : Decreasing body mass index is associated with cerebrospinal fluid markers of Alzheimer's pathology in MCI and mild dementia.

\section{THESE}

préparée sous la direction du Professeur Julius Popp avec la co-direction du Professeur Armin von Gunten

et présentée à la Faculté de biologie et de médecine de I'Université de Lausanne pour l'obtention du grade de

DOCTEUR EN MEDECINE

par

Jules Mathys

Médecin diplômé de I'Université Catholique de Louvain (Belgique)

Originaire de Belgique 
Titre de la thèse : Decreasing body mass index is associated with cerebrospinal fluid markers of Alzheimer's pathology in MCI and mild dementia.

\section{CONTEXTE :}

Plusieurs études ont identifié une association entre I'Indice de Masse Corporelle (IMC) et l'incidence ainsi que la sévérité de la maladie d'Alzheimer (MA), mais cette relation n'est actuellement pas encore pleinement comprise.

\section{OBJECTIFS de I'ETUDE :}

L'objectif primaire de cette étude était d'établir la possible association entre I'IMC et les biomarqueurs de la MA dans le liquide céphalo-rachidien (LCR) chez des sujets avec et sans troubles cognitifs. L'objectif secondaire de cette étude était d'investiguer si l'IMC pouvait contribuer à améliorer la précision d'un modèle clinique afin de prédire l'occurrence pathologique des biomarqueurs de la MA dans le LCR des patients en consultation de la mémoire souffrant de troubles cognitifs.

\section{MÉTHODE :}

107 sujets âgés avec des déficits cognitifs (dont 91 patients en consultation de la mémoire avec des troubles cognitifs légers [MCI] et 16 patients souffrent d'une démence légère de type Alzheimer) et 55 sujets volontaires sains ont été inclus dans l'étude. Tous les sujets ont reçu une évaluation clinique et neuropsychologique exhaustive ainsi qu'une ponction lombaire afin d'y récolter les biomarqueurs de la MA dans le LCR. Des régressions linéaires multiples et des analyses ROC ont été menées afin d'établir l'association entre I'IMC et les biomarqueurs de la MA dans le LCR.

\section{RÉSULTATS :}

L'IMC est corrélée positivement avec les taux d'A 442 dans le LCR et négativement avec tau and P-tau181 chez les participants avec des troubles cognitifs. Ces associations sont indépendantes de l'âge, le sexe, le niveau éducatif, le type et la sévérité des troubles cognitifs, ces facteurs de risques cérébro-vasculaires et la présence de I'allèle APOE\&4. De plus, I'IMC a amélioré de façon significative la sensibilité et la spécificité d'un modèle multifactoriel prédisant la présence d'un profil pathologique des biomarqueurs de la MA dans le LCR.

\section{CONCLUSION:}

Un faible IMC est associé avec une pathologie cérébrale de la MA plutôt qu'avec un trouble cognitif chez des sujets âgés avec un MCI et une démence légère. Avec d'autres facteurs cliniques, un IMC en diminution pourrait aider le clinicien à identifier des patients avec un trouble cognitif en lien avec la MA. 


\title{
Decreasing body mass index is associated with cerebrospinal fluid markers of Alzheimer's pathology in MCI and mild dementia
}

\author{
Jules Mathys $^{\mathrm{a}, 1}$, Mehdi Gholamrezaee ${ }^{\mathrm{b}, 2}$, Hugues Henry ${ }^{\mathrm{c}, 3}$, Armin von Gunten ${ }^{\mathrm{a}, 1}$, Julius Popp ${ }^{\mathrm{a}, \mathrm{d}, *}$ \\ a Old Age Psychiatry, Department of Psychiatry, University Hospital of Lausanne, Lausanne, Switzerland \\ b Departement of Psychiatry, University Hospital of Lausanne, Lausanne, Switzerland \\ c Departement of Laboratory Medicine, University Hospital of Lausanne, Lausanne, Switzerland \\ d Geriatric Psychiatry, Geneva University Hospitals and University of Geneva, Switzerland
}

\section{A R T I C L E I N F O}

Section Editor: Christian Humpel

Keywords:

Alzheimer's disease

Body mass index

Cerebrospinal fluid biomarkers

Mild cognitive impairment

Weight loss

Dementia

\begin{abstract}
A B S T R A C T
Background: Several studies have identified an association between body mass index (BMI) and the incidence and severity of Alzheimer's disease (AD) but this relationship is not fully understood.

Objective: The primary objective of this study was to assess the possible association between BMI and cerebrospinal fluid (CSF) biomarkers of AD pathology in subjects with normal cognition and cognitive impairment. The secondary objective was to test whether BMI may contribute to improve the accuracy of a clinical model to predict AD pathology in memory clinic patients with cognitive impairment.

Method: One hundred and seven elderly subjects with cognitive impairment (91 memory clinic patients with mild cognitive impairment [MCI] and 16 with dementia of AD type) and 55 cognitively healthy volunteers were included in this study. All subjects received a comprehensive clinical and neuropsychological evaluation and a lumbar puncture for CSF biomarker analysis. Multiple linear regressions and receiver operating characteristic (ROC) analyses were carried out to assess the association between BMI and the CSF biomarkers of AD pathology. Results: BMI was positively correlated with the CSF levels of $A \beta_{42}$ and negatively with tau and P-tau181 in participants with cognitive impairment. The associations were independent of age, sex, educational level, type and severity of cognitive impairment, cerebrovascular risk factors and the presence of the APOE 4 allele. Furthermore, BMI significantly improved the sensitivity and specificity of a multi-factorial model to predict the presence of an AD CSF biomarker profile.

Conclusion: Lower BMI is associated with cerebral AD pathology rather than with cognitive impairment in elderly subjects with MCI and mild dementia. Along with other clinical factors, decreasing BMI may help the clinician to identify patients with cognitive impairment due to AD.
\end{abstract}

\section{Introduction}

Alzheimer disease (AD) is the most common cause of dementia in older age (60-80\% of cases) (Prince et al., 2013). The development of $\mathrm{AD}$ is characterized by a long asymptomatic phase followed by a prodromal stage with beginning cognitive decline and mild cognitive impairment (MCI). Cerebral accumulation of amyloid-beta (A $\beta$ ) plaques, neuronal cell death, and aggregation of hyperphosphorylated tau as neurofibrillary tangles are core features of the $\mathrm{AD}$ brain pathology
(Musiek and Holtzman, 2015). The cerebro-spinal fluid (CSF) concentrations of $A \beta_{42}$, tau, and P-tau181 represent well-established biomarkers of $\mathrm{AD}$ and allow for the detection of the disease specific pathology years before the dementia stage (Scheltens et al., 2016).

The body mass index (BMI) is a clinical measure defined by a person's weight in relation to height. Numerous affections have been associated with BMI. Regarding the relation of BMI with $\mathrm{AD}$, an apparent "obesity paradox" has been described, i.e. high BMI is associated with risk of (AD) dementia during mid-life whereas in late-life there is an

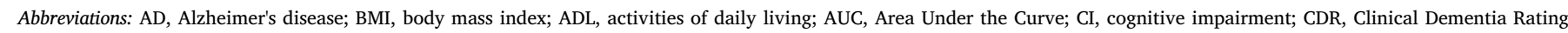

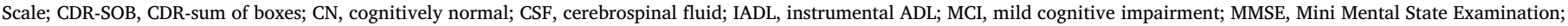
ROC, Received Operating Characteristic

* Corresponding author at: Geriatric Psychiatry, Geneva University Hospitals, Chemin du Petit-Bel-Air 2, CH-1226 Thônex, Switzerland.

E-mail address: julius.popp@chuv.ch (J. Popp).

${ }^{1}$ Service Universitaire de Psychiatrie de l'Âge Avancé, Site de Cery, 1008 Prilly, Switzerland.

${ }^{2}$ Département de Psychiatrie, Site de Cery, 1008 Prilly, Switzerland.

${ }^{3}$ Département des Laboratoires, Bugnon 21, 1011 Lausanne, Switzerland.
} 
association between low BMI and clinically diagnosed AD (Fitzpatrick et al., 2009). More precisely a high BMI in midlife is associated with an increased risk of developing diabetes, vascular pathology, hypertension and hypercholesterolemia that are all independent risk factors for developing cognitive impairment and $\mathrm{AD}$ dementia in later life. High $\mathrm{BMI}$ in midlife has been also associated with cerebral metabolic and structural changes that may early contribute to the development of $\mathrm{AD}$ pathology (Erol, 2008). However, in later life, weight loss and low BMI appear to be associated with severity of cognitive impairment or dementia (Albanese et al., 2013; Luchsinger et al., 2008; Smith et al., 2014), faster cognitive decline (Deschamps et al., 2002), and with postoperative delirium (Chung et al., 2015; Juliebo et al., 2009) Furthermore, weight loss may be an early event in cognitive decline, and may precede the dementia diagnosis (Buchman et al., 2006; Johnson et al., 2006; Knopman et al., 2007).

While weight loss in older people with cognitive impairment may be detrimental and increase frailty, the relationships between low BMI and cognitive decline, and their causes are not well understood. Possible explanations are that low BMI may result from cognitive impairment and decline with consequences on nutrition and everyday activities; or that specific brain pathology such as $\mathrm{AD}$ pathology may result in systemic metabolic changes with consequent weight loss. Evidence supporting this later hypothesis was found in the "Alzheimer's Disease Neuroimaging Initiative" (ADNI) cohort lower BMI was associated with CSF biomarkers of AD pathology, in both cognitively normal and impaired patients (Ewers et al., 2012; Vidoni et al., 2011). Also, a post mortem study has found that high amount of cerebral AD pathology is correlated to low BMI (Buchman et al., 2006).

Diagnosis of AD based on clinical and neuropsychological features (McKhann et al., 2011) has limited accuracy in discriminating between cognitive impairment due to AD pathology and cognitive impairment of other causes (Beach et al., 2012). This is particularly the case in MCI, a group in which the etiology of cognitive impairment and the prognosis are very heterogeneous (Winblad). Recently proposed revised criteria both include the use of biomarkers to increase the diagnostic and predictive accuracy in patients with dementia; and extend the possible diagnosis of the disease to the prodromal stage of $\mathrm{AD}$, i.e. to MCI due to AD (Albert et al., 2011; McKhann et al., 2011). However, biomarkers are not always available, or their use may be limited by contraindications, patient's refusal, and costs. Therefore, the identification of additional clinical factors associated with $\mathrm{AD}$ pathology may help to improve clinical diagnostic accuracy and to identify, among memory clinic patients, those at high risk of having AD. In this context, BMI, or BMI variation over time along with other clinical features may contribute to improve early diagnosis and differential diagnosis of AD.

The aim of this study was to assess the relationships between BMI and AD CSF biomarkers related to amyloid pathology, neuronal injury, and tau hyperphosphorylation. In addition, we addressed the question whether BMI can contribute to improve predictive models of $\mathrm{AD}$ pathology in elderly cognitively normal (CN) subjects and in memory clinic patients with MCI and mild dementia.

\section{Material and methods}

\subsection{Subjects}

One hundred and sixty two community-dwelling subjects aged 50 years or older, 55 of them being $\mathrm{CN}$, and 107 memory clinic patients with cognitive impairment (CI, of which 91 subjects were diagnosed with MCI and 16 with mild dementia of AD type) were included in a prospective longitudinal cohort study aiming at investigating clinical and biological factors associated with $\mathrm{AD}$ pathology. The study was approved by the local ethics committee and informed consent was obtained from all participants.

The study participants with CI were recruited among outpatients with cognitive impairment referred to the Memory Clinics, Department of Psychiatry and the Department Clinical Neurosciences, University Hospital of Lausanne for investigation of their cognitive complaints. Exclusion criteria were severe concomitant neurological, psychiatric or somatic comorbidities that could affect cognition. All subjects underwent a full clinical evaluation, made by senior neurologists, old age psychiatrists or geriatricians. The clinical examination and the Hospital Anxiety and Depression Scale were used to assess the presence of relevant depression or anxiety symptoms (Zigmond and Snaith, 1983). Trained neuropsychologists performed a neuropsychological assessment. The neuropsychological assessment included the Mini Mental State Examination (MMSE), the Buschke Double Memory Test (Buschke et al., 1997), the digit span forward and backward (Wechsler, 1955), the Stroop Test (Stroop, 1935), the letter fluency task (Cardebat et al., 1990), and the Trail Making Tests A and B (Reitan, 1958). The functional assessment included the activities of daily living (ADL) and instrumental ADL (IADL) (Lawton and Brody, 1969) as well as the CDR (Morris, 1993). The clinical examination, the neuropsychological test battery, ADL and IADL were used to determine the CDR and the CDRsum of boxes ( $-\mathrm{SOB}$ ) scores and to verify inclusion and exclusion criteria. All tests and scales used in this study are validated and widely used in the field. The CI subjects were further divided into three CI subgroups according to their cognitive profile: amnestic single domain CI $(n=36)$, non-amnestic CI $(n=10)$, or mixed impairments (i.e. amnestic multidomain; $n=60$ ).

BMI was measured and a standard blood sample was taken on the day of the lumbar puncture, after overnight fasting.

The diagnosis of MCI or of mild dementia was made by a consensus conference of senior physicians and neuropsychologists prior to the inclusion in the study, based upon neuropsychological and clinical evaluations according to published criteria (McKhann et al., 2011; Winblad et al., 2004). Patients with a positive diagnosis of MCI or mild dementia were considered together, as the CI group, in accordance with revised concepts of $\mathrm{AD}$ considering the disease as a biological continuum of developing cerebral pathology without clear differences between MCI and mild dementia (Albert et al., 2011). All the subjects in the CI group had memory impairment ( $\geq 1.5$ SD below the means adjusted for sex, age and education in the verbal memory tasks of Buschke Double Memory Test (Buschke et al., 1997)), and/or impairment in other cognitive domains such as executive tasks or language skills. All subjects in the CI group also had a Clinical Dementia Rating Scale (CDR) (Morris, 1993) score of at least 0.5 (subjects with a CDR score of 0.5 were categorized as MCI subjects, and subjects with a CDR score of 1 were categorized as mild dementia subjects).

$\mathrm{CN}$ subjects were community dwelling healthy volunteers recruited by advertisement or among relatives of memory clinic patients. The clinical and neuropsychological assessment included the same tests battery and questionnaires as for the CI participants. The CN participants had no history or evidence of cognitive decline and a CDR score of 0 .

\subsection{Blood and cerebrospinal fluid collection}

Venous and lumbar punctures were performed between 8:30 and 9:30 am after overnight fasting at the recruiting memory centres. For lumbar puncture, a standardized technique with a $22 \mathrm{G}$ "atraumatical" spinal needle and a sitting or lying position was applied (Popp et al., 2007). Cerebrospinal fluid (CSF) was collected for analysis using polypropylene tubes. Routine CSF cell count and protein quantification was performed. Remaining CSF was centrifuged, frozen in aliquots, and stored at $-80{ }^{\circ} \mathrm{C}$ until assay.

\subsection{CSF biomarker measure and APOE genotyping}

$\mathrm{A} \beta_{42}$, tau, and P-tau181 concentrations in the CSF samples were measured by ELISA, using commercially available assays (Fujirebio, Gent, Belgium). Biomarker ratios (tau/A $\beta_{42}$ and P-tau181/A $\beta_{42}$ ) as 
markers of concomitant presence of amyloid pathology and tau pathology (Scheltens et al., 2016; Duits et al., 2014) were also calculated. Different approaches have been proposed to define the AD CSF biomarker profile, but there are still no universal cutoffs established for CSF biomarkers (Duits et al., 2014). As there may be significant differences between centres, it is recommended to define centre specific cutoffs which should be confirmed by longitudinal clinical follow-up evaluations and, ideally, by post-mortem histology (Molinuevo et al., 2014). Accordingly, we determined the centre cutoff for CSF P-tau181/ $A \beta_{42}$ (i.e., 0.0779), we confirmed this cutoff value by using longitudinal clinical follow-up data, and compared it to the literature. Briefly, the centre cutoff was determined in a previous study using data from $\mathrm{N}=120$ subjects ( 48 healthy volunteers with normal cognition and 72 memory clinic patients with MCI or mild dementia of AD type) as the value that optimized the Youden index of the Received Operating Characteristic (ROC) curve of prediction of CDR categories (CDR $=0 \mathrm{vs}$ CDR > 0; Area Under the Curve $[\mathrm{AUC}]=0.789$, accuracy: 0.733 ) (Popp et al., 2017; Tautvydaite et al., 2017). This cutoff was further confirmed to be a highly significant predictor of cognitive decline (i.e. change in global cognition as measured by MMSE at a follow-up visit 18 months after inclusion) after considering multiple possible confounders (Beta $=-0.436$; $<<0.00001$; unpublished data). The determined cutoff for P-tau181/A $\beta_{42}$ was similar to values previously reported by other (Duits et al., 2014).

To evaluate possible interactions and effects of the APOE genotype on the addressed relationships, leukocyte genomic DNA was isolated from EDTA blood with the Qiagen blood isolation kit (Qiagen, Hilden, Germany) and the APOE genotype was determined as previously described (Jansen et al., 2015; Popp et al., 2010).

\subsection{Follow-up visits}

To address the question whether baseline AD CSF biomarker levels were associated with BMI changes over time, and whether lower BMI at baseline may indicate a risk of rapid cognitive decline, we used clinical follow-up data available for a subset of 61 participants, of which 28 were in the $\mathrm{CN}$ group and 33 in the $\mathrm{CI}$ group. The clinical and neuropsychological follow-up evaluation was performed by the same methods and tests used at the first visit. In some cases, the administration full neuropsychological test battery was not possible due to the participant's cognitive impairment. The MMSE score was available in all participants and used as a measure of global cognition.

\subsection{Statistics}

\subsubsection{Between-group comparisons}

The between-group (CN vs CI) differences in continuous variables were assessed using Student's $t$-test for independent samples and associations among categorical variables were analyzed by Pearson's $\chi^{2}$-test of independence.

\subsubsection{Correlations between BMI and AD CSF biomarkers}

The strength of the linear association between BMI and AD CSF biomarkers was assessed using the Pearson linear correlation coefficient. The correlations were performed for the whole population, as well as for the $\mathrm{CN}$ and $\mathrm{CI}$ groups separately. The Pearson's correlation coefficient was also calculated between BMI and the other continuous variables.

\subsubsection{Associations of BMI and AD CSF biomarkers level}

In order to evaluate the contribution of BMI in predictive models of the level of $\mathrm{AD}$ CSF biomarkers, multiple linear regressions were used. All models for predicting $A \beta_{42}$, tau and P-tau181 (dependent variables) were adjusted for age, gender, number of education years, severity of cognitive impairment (MMSE score), presence of ApoE\&4 allele and comorbidities (i.e. history of high blood pressure, hypercholesterolemia, diabetes, smoking and stroke). In order to determine the best final models for each dependent variable, a selection was performed using a backward elimination approach (conservative method for choosing the best potential model).

Fundamental assumptions of the regressions (satisfactory normal distribution and constant variance for residuals) were assessed by graphical means for final models. Whenever the fit diagnostics was not satisfactory, the uncertainty of estimated parameters were evaluated based on a large number of bootstrap iterations $(n=10,000)$. Analyses were performed for the whole population, as well as separately for $\mathrm{CN}$ and CI subjects (referred to as CN and CI groups).

\subsubsection{Accuracy of models predicting the AD CSF biomarker profile with and without $B M I$}

A Binary logistic regression model (Generalized Linear Model with logit link), integrating age, sex, number of education years, MMSE score and presence of ApoE\&4 allele, was used to predict the AD CSF biomarker profile (dichotomous outcome), in CI subjects. After adjusting this model, the sensitivity and specificity measurements were performed both with and without inclusion of BMI to measure the predictive power of BMI on the outcome. The ROC method was used to compare the accuracy of the two models.

2.5.5. BMI changes in relation to AD CSF biomarkers and cognitive decline

Finally, in order to explore whether the AD CSF biomarkers levels were associated with BMI changes over time, BMI change from baseline was included in the multiple linear regression models. This was performed in a subset of 61 participants $(28 \mathrm{CN}$ and $33 \mathrm{CI}$ ), for which measures of BMI at follow-up was available. In addition, in order to assess whether lower BMI at baseline was associated with cognitive decline, we performed a multivariate regression analysis with MMSE score decline as the dependent variable and including BMI, age, sex, ApoE\&4 status and CSF AD profile as predictor variables (these predictors were selected using the backward elimination approach).

For all analyses, $\alpha \leq 0.05$ was accepted as nominal level of significance; all statistical analyses were performed using SPSS 23 for Windows software.

\section{Results}

\subsection{Subjects' characteristics}

Subjects' characteristics are shown in Table 1. The CI and CN groups did not differ for sex, number of education years, BMI, history of arterial hypertension, stroke and smoking, but they differed for age, MMSE score, CDR score, history of diabetes, history of hypercholesterolemia and the presence of the ApoE\&4 allele. The level of the three investigated $\mathrm{AD}$ CSF biomarkers and the $\mathrm{AD}$ CSF profile were also significantly different in the two study groups (Table 1).

\subsection{Correlations between BMI and AD CSF biomarkers}

Regarding the whole population, the correlation coefficients ( $\rho$ ) between $\mathrm{BMI}$ and the AD CSF biomarkers were significant. Indeed, BMI was positively correlated with $A \beta_{42}(\rho=0.250 ; p$-value $\leq 0.001)$, and negatively associated with tau $(\rho=-0.260$; $\mathrm{p}$-value $\leq 0.001)$ and Ptau181 $(\rho=-0.221$; $p$-value $\leq 0.01)$. Correlation coefficients for the $\mathrm{CN}$ and CI groups are shown in Table 2, and graphically represented in Figs. 1, 2 and 3. In the CI group, BMI was positively correlated with $\mathrm{A} \beta_{42}$ and negatively correlated with tau, P-tau181 and both biomarkers ratios: tau $/ A \beta_{42}$ and $\mathrm{P}$-tau181/A $\beta_{42}$. Correlations within the CI group appeared to be stronger than for the whole population. By contrast, none of the correlations were statistically significant in the CN group.

BMI was not correlated either with age, hypercholesterolemia, number of education years, gender, MMSE, CDR, CDR-SOB, or with the presence of an ApoE\&4 allele. History of high blood pressure was 
Table 1

Subjects' characteristics.

\begin{tabular}{|c|c|c|c|c|}
\hline & $\mathrm{CN}(\mathrm{n}=55)$ & $\mathrm{CI}(\mathrm{n}=107)$ & p-Value (CN vs $\mathrm{CI}$ ) & Subgroup with follow-up visits \\
\hline \multicolumn{5}{|l|}{ Measure, unit } \\
\hline Gender $(\mathrm{f} / \mathrm{m}), \mathrm{n}$ & $37 / 18$ & $59 / 48$ & n.s. ${ }^{a}$ & $38 / 23$ \\
\hline Type of CI (amnestic/non-amnestic/mixed), n & - & $36 / 10 / 60$ & - & $13 / 2 / 18$ \\
\hline Mean age (SD), years & $66.8(7.9)$ & $73.9(6.6)$ & $<0.001^{\mathrm{b}}$ & $69.5(7.7)$ \\
\hline Mean education years (SD), $\mathrm{n}$ & $12.8(2.6)$ & $12.1(2.7)$ & n.s. ${ }^{\text {b }}$ & $12.8(2.8)$ \\
\hline Mean MMSE (SD), points & $28.5(1.6)$ & $25.5(3.5)$ & $<0.001^{\mathrm{b}}$ & $27.3(2.6)$ \\
\hline Mean CDR-SOB (SD), points & $0(0)$ & $2.1(2.2)$ & $<0.001^{\mathrm{b}}$ & $0.8(1.7)$ \\
\hline Mean BMI (SD), $\mathrm{kg} / \mathrm{m}^{2}$ & $25.1(4.3)$ & $25.4(4.6)$ & n.s. ${ }^{\text {b }}$ & $25.7(4.8)$ \\
\hline HBP (yes/no), n & $14 / 41$ & $32 / 57$ & n.s. ${ }^{\mathrm{a}}$ & $20 / 40^{\mathrm{c}}$ \\
\hline Diabetes (yes/no), n & $1 / 53^{\mathrm{c}}$ & $12 / 88$ & $<0.05^{\mathrm{a}}$ & $3 / 58$ \\
\hline Hypercholesterolemia (yes/no), $\mathrm{n}$ & $9 / 43^{c}$ & $27 / 48$ & $<0.01^{\mathrm{a}}$ & $21 / 40$ \\
\hline History of stroke (yes/no), n & $2 / 53$ & $4 / 99^{c}$ & n.s. ${ }^{\mathrm{a}}$ & $2 / 58^{c}$ \\
\hline History of smoking (yes/no), $\mathrm{n}$ & $30 / 25$ & $38 / 57^{\mathrm{c}}$ & n.s. ${ }^{a}$ & $33 / 27^{\mathrm{c}}$ \\
\hline ApoE\&4 gene (non-carrier/carrier), $\mathrm{n}$ & $46 / 8^{c}$ & $57 / 43^{c}$ & $<0.001^{\mathrm{a}}$ & $41 / 17^{c}$ \\
\hline \multicolumn{5}{|l|}{ CSF biomarkers, unit } \\
\hline Mean $A \beta_{42}$ level (SD), ng/1 & $968.5(213.3)$ & $759.5(348.2)$ & $<0.001^{\mathrm{b}}$ & $855.4(284.4)$ \\
\hline Mean hTau level (SD), ng/l & $268.4(187.2)$ & $501.5(348.2)$ & $<0.001^{\mathrm{b}}$ & $396.5(303.4)$ \\
\hline Mean P-tau181 level (SD), ng/1 & $51.3(21.2)$ & $73.2(40.1)$ & $<0.001^{\mathrm{b}}$ & $65.0(43.7)$ \\
\hline CSF AD profile $(y / n), n$ & $5 / 50$ & $60 / 47$ & $<0.001^{\mathrm{a}}$ & $20 / 40^{\mathrm{c}}$ \\
\hline
\end{tabular}

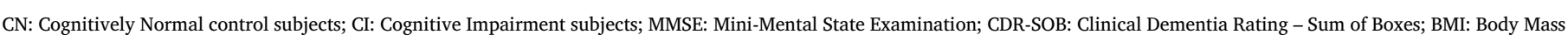
Index; HBP: history of high blood pressure; CSF AD: Cerebrospinal fluid AD profile; SD: standard deviation.

$\mathrm{n}=$ number of subjects; n.s.: nonsignificant.

${ }^{\text {a }}$ Pearson $\chi^{2}$ test

b $t$-Test.

${ }^{\mathrm{c}}$ Data is missing for one or more subjects.

Table 2

Correlations between BMI and CSF AD biomarkers for cognitively normal and cognitively impaired subjects.

\begin{tabular}{lll}
\hline Pearson correlation coefficient $\rho$ for & CN $(\mathrm{n}=55)$ & CI $(\mathrm{n}=107)$ \\
\hline BMI vs $\mathrm{A} \beta_{42}$ & 0.131 (n.s.) & $0.335^{* * * *}$ \\
BMI vs tau & -0.137 (n.s.) & $-0.338^{* * * *}$ \\
BMI vs P-tau181 & -0.167 (n.s.) & $-0.268^{* *}$ \\
BMI vs tau/A $\beta_{42}$ ratio & -0.180 (n.s.) & $-0.330^{* *}$ \\
BMI vs P-tau181/A $\beta_{42}$ & -0.210 (n.s.) & $-0.319^{* *}$ \\
\hline
\end{tabular}

Note. CN: Cognitively Normal control subjects; CI: Cognitive Impaired subjects; BMI: Body Mass Index;

$\mathrm{n}=$ number of subjects; n.s.: nonsignificant.

*** $\mathrm{p} \leq 0.01$.

**** $\mathrm{p} \leq 0.001$.

surprisingly associated with low BMI but subsequent analyses were made in order to clarify if history of high blood pressure could be a confounding factor; consequent results demonstrated that it was not correlated with CSF biomarkers or any other factor.

\subsection{Associations of BMI with AD CSF biomarkers level}

The backward elimination approach showed that comorbidities were not significant predictors in any of the models, and therefore, these factors were not included in the final models (results for these predictors are not shown). The regression coefficients $\beta$ for the other selected predictors and their associated significance levels are presented in Table 3, for both the CN and CI groups.

Multiple linear regression models confirmed the Pearson's associations between BMI and 2 of the 3 AD CSF biomarkers: $A \beta_{42}(\beta=0.24$, $\mathrm{p}<0.01)$ and tau $(\beta=-0.27, \mathrm{p}<0.01)$. Ptau-181 was negatively correlated with BMI but not significantly in this model $(\beta=-0.19$, $\mathrm{p}=0.055$ ). When considering the CI subgroups (single domain amnestic CI, non-amnestic CI and mixed CI), the effect of BMI reached significance in the amnestic CI $(\mathrm{n}=36 ; \beta=0.46, \mathrm{p}<0.01)$ and mixed CI ( $n=60 ; \beta=0.36, p<0.01)$ subgroups, but not in the nonamnestic CI group $(n=10 ; \beta=0.46, p=0.886)$. Although the MMSE score was used to adjust linear regression models, using CDR-SOB instead of the MMSE score did not change the associations and their corresponding directions and magnitudes (results not shown).

\subsection{Accuracy of models predicting the AD CSF biomarker profile with and without BMI}

ROC analyses predicting pathological AD CSF biomarker profile using CI group showed $84.62 \%$ and $83.61 \%$ sensitivity and specificity, respectively (Fig. 4). In these analyses, by excluding the BMI from the model and comparing the result with the model using BMI, we observed that BMI accounted for a sensitivity and specificity improvement of $14.85 \%$ and $13.84 \%$, respectively (Fig. 4). When performed separately in the subgroup with MCI, the ROC analysis showed a sensitivity of $88.64 \%$ and a specificity of $78.05 \%$ after inclusion of BMI. Adding BMI accounted for a sensitivity and specificity improvement of $11.37 \%$ and $8.02 \%$, respectively.

\subsection{BMI as a predictor of cognitive decline and BMI changes in relation to AD CSF biomarkers}

Regarding the analysis in the subset of 61 subjects with measures of BMI at follow-up (mean $[ \pm \mathrm{SD}]$ follow-up time was $18.5[ \pm 6.5]$ months), higher tau and P-tau181 levels at baseline were significantly associated with decreasing BMI from baseline after controlling for time to follow-up visit $(\beta=-0.361 ; p<0.01$ and $\beta=-0.336$; $\mathrm{p}<0.01$, respectively). Four out of the 33 subjects with MCI transitioned to mild dementia between baseline and follow-up. BMI change at follow-up was correlated with changes in MMSE score (Spearman correlation: $\mathrm{r}=0.578 ; \mathrm{p}<0.0005$ ) in the CI group.

\section{Discussion}

We found BMI to be positively associated with cerebral amyloid pathology and negatively associated with tau hyperphosphorylation and neuronal injury as measured by CSF biomarkers in the subjects with CI. The associations remained significant after controlling for several possible confounders. Moreover, including BMI in a multivariate model substantially improved the classification of participants with CI 


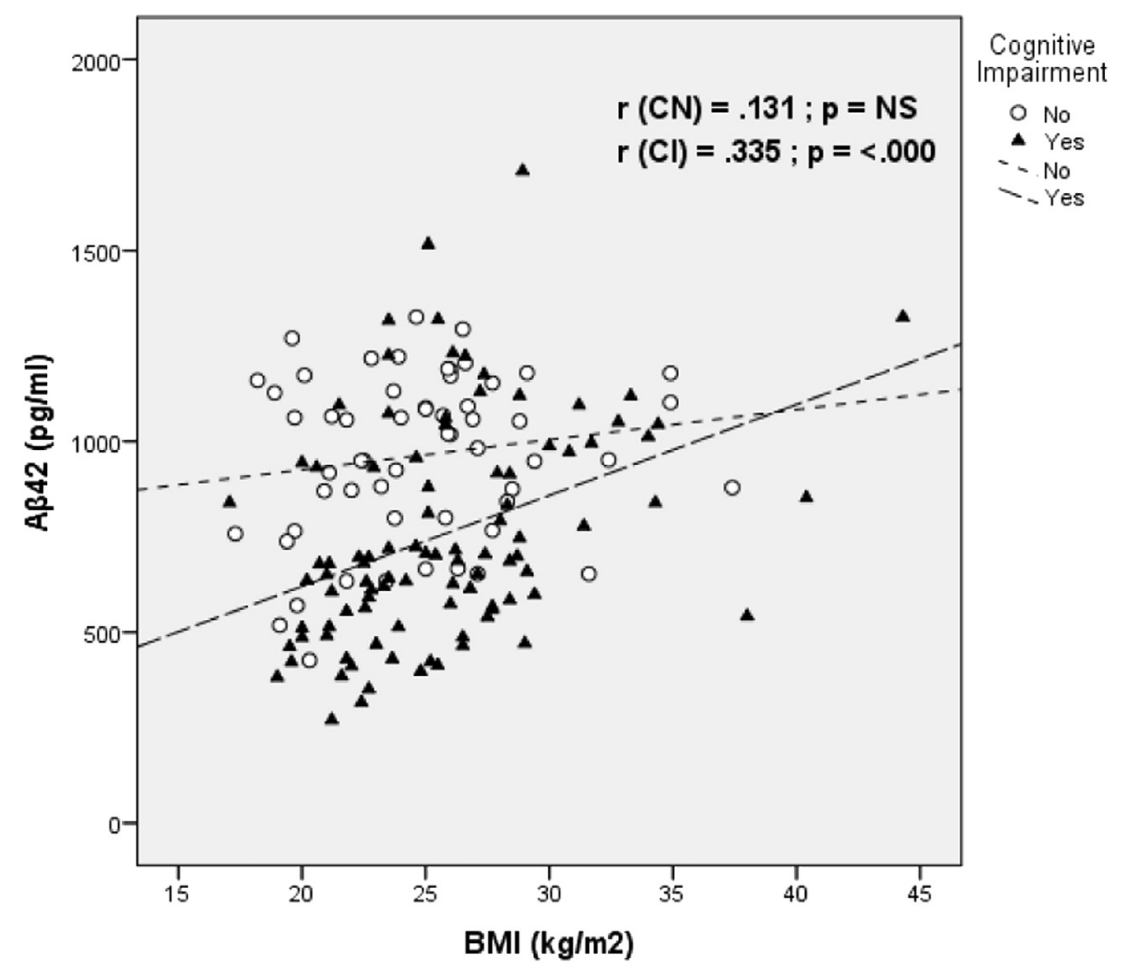

Fig. 1. Scatterplot showing CSF $A \beta_{42}(\mathrm{pg} / \mathrm{ml})$ versus Body Mass Index $\left(\mathrm{kg} / \mathrm{m}^{2}\right)$ for cognitively normal $(\mathrm{CN})$ and cognitively impaired $(\mathrm{CI})$ patients. according to the presence of an AD CSF biomarker profile. Preliminary analyses of longitudinal data in a subsample showed BMI decrease over time in relation to CSF tau and P-tau181, and in association with cognitive decline.

Weight change in clinically diagnosed AD dementia has been described previously and associations between weight loss and disease severity and progression have been reported (White et al., 1996; Soto et al., 2012). General physical frailty (low weight, physical fatigue, sarcopenia, lower gait speed and overall muscular strength) in AD could result from the progressive loss of cognitive function with consequences

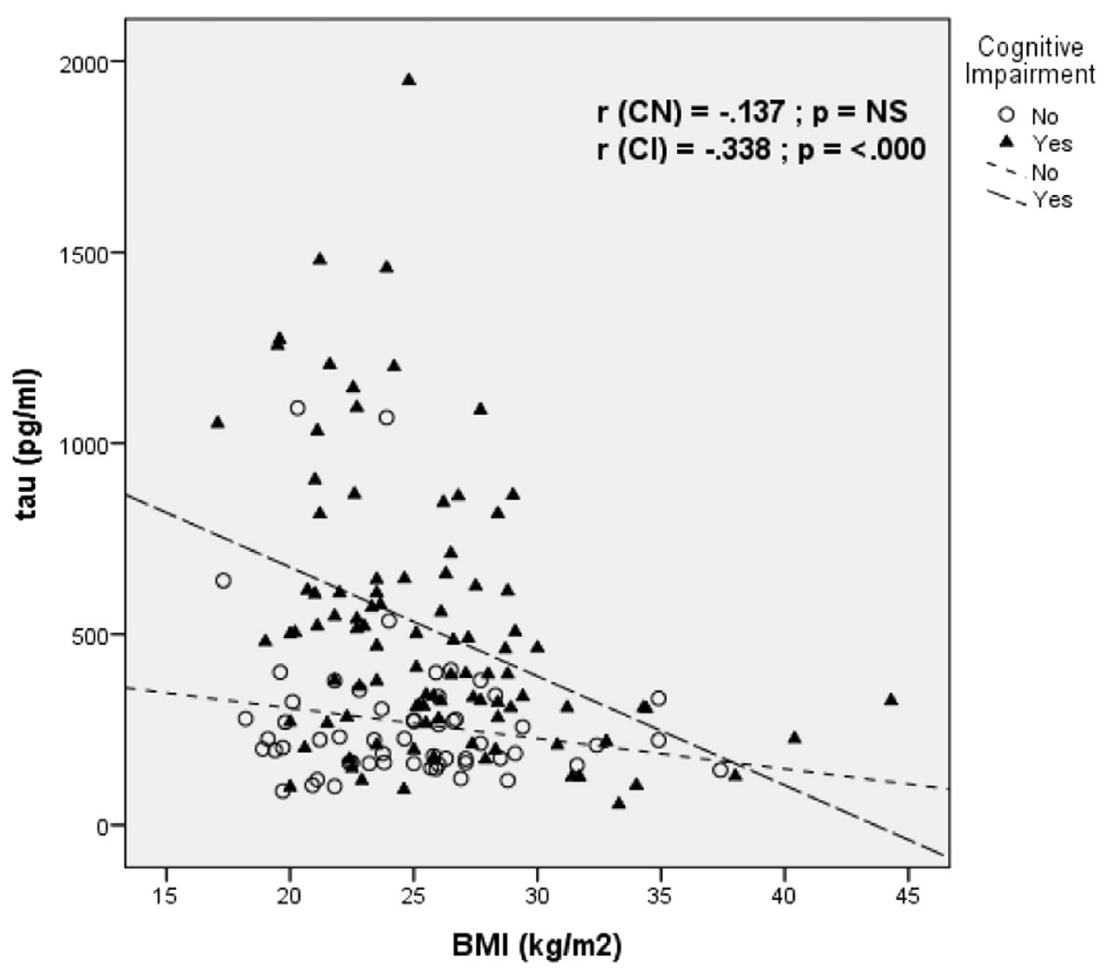

on nutrition and everyday activities. Furthermore, neuropsychiatric symptoms such as apathy and depression can affect food intake and are often precursors of cognitive decline (Donovan et al., 2014; Geda et al., 2014). However, impairment of the general nutritional status is mainly observed in the more advanced stages of AD dementia (Marino et al., 2015).

While weight loss in AD may be relate to cognitive and functional impairment as well as psychiatric symptoms, all with possible consequences on nutrition, another possible explanation is that the development of cerebral AD pathology directly affects the organism's

Fig. 2. Scatterplot showing CSF tau (pg/ml) versus Body Mass Index $\left(\mathrm{kg} / \mathrm{m}^{2}\right)$ for cognitively normal $(\mathrm{CN})$ and cognitively impaired (CI) patients. 


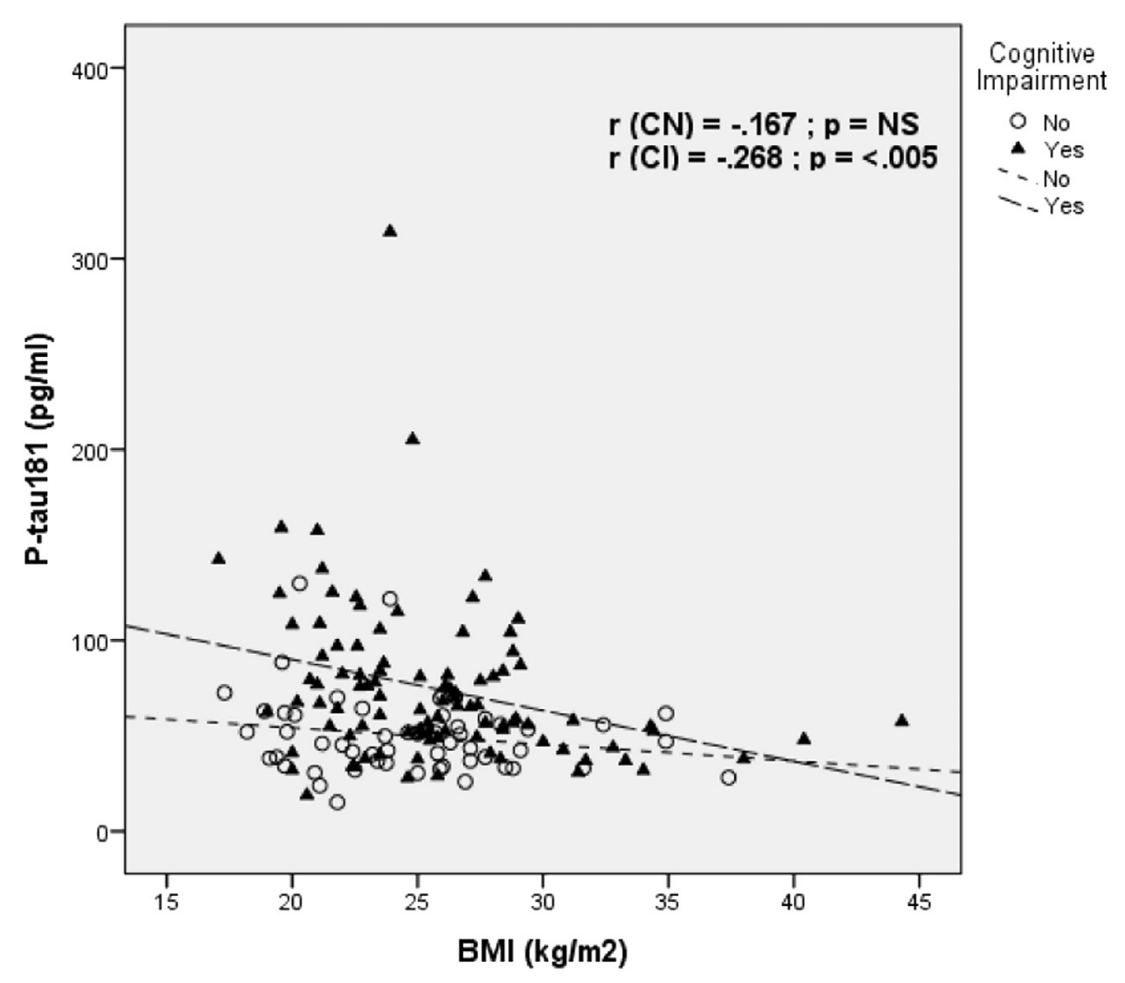

Fig. 3. Scatterplot showing CSF P-tau181 (pg/ml) versus Body Mass Index $\left(\mathrm{kg} / \mathrm{m}^{2}\right)$ for cognitively normal $(\mathrm{CN})$ and cognitively impaired (CI) patients. metabolism. One of the early neuropathological changes in $\mathrm{AD}$ is the degeneration of the medial temporal lobe cortex (Duara et al., 2008). This area of the brain may also be related to weight loss (Grundman et al., 1996). The medial temporal lobe, the entorhinal cortex, and the hypothalamus host structures involved in the regulation of appetite and energy metabolism (Ishii and Iadecola, 2015; Val-Laillet et al., 2015). Alterations in the synthesis and metabolism of glucose have been described in $\mathrm{AD}$, and may be explained by pathological changes in these brain structures (González-Domínguez et al., 2015; Sato and Morishita, 2015). Also, misfolded and aggregated amyloid proteins trigger immune responses at systemic and CNS levels that may significantly alter food intake and overall metabolism as with other known chronic inflammatory states (Heneka et al., 2015). Inflammation, along with other pathological processes related to $\mathrm{AD}$, may increase the susceptibility to developing delirium (Popp, 2013), and lower BMI has been found to be associated with increased risk of delirium in the elderly (Chung et al., 2015; Oh et al., 2015).

While the association between clinically diagnosed $\mathrm{AD}$ dementia and low BMI has been reported in several publications, only a few studies have addressed the possible associations between cerebral AD pathology and BMI, or BMI changes over time. A post mortem autopsy study found levels of cerebral AD pathology to be associated with BMI proximate to death, but other pathologies such as Lewy body pathology and cerebral infarctions were not associated with BMI (Buchman et al., 2006). Intriguingly, in living older subjects, a study including participants with subjective memory impairment and MCI found high BMI in association with higher amounts of fibrillar insoluble protein aggregates as measured by PET (Merrill et al., 2016). Using more specific amyloid imaging by PET, another study found low BMI to be associated with greater cortical amyloid burden in cognitively normal older subjects (Hsu et al., 2016). To our knowledge, the relationships between BMI and CSF biomarkers of AD pathology have been investigated and specifically addressed in only one cohort (ADNI) by two different groups (Ewers et al., 2012; Vidoni et al., 2011), and no longitudinal results have been published so far. In line with the results from the ADNI cohort, our results in a more heterogeneous group of participants

Table 3

Standardized regression coefficients $\beta$ for selected predictors calculated from multiple linear regression analyses, for cognitively normal and cognitively impaired subjects.

\begin{tabular}{|c|c|c|c|c|c|c|}
\hline \multirow[b]{2}{*}{ Dependent variable } & \multicolumn{3}{|c|}{$\mathrm{CN}(\mathrm{n}=55)$} & \multicolumn{3}{|l|}{ CI $(\mathrm{n}=107)$} \\
\hline & $\mathrm{A} \beta_{42}$ & tau & P-tau181 & $\mathrm{A} \beta_{42}$ & tau & P-tau181 \\
\hline \multicolumn{7}{|l|}{ Predictors } \\
\hline BMI & $\mathrm{n} / \mathrm{a}$ & $-0.25(\mathrm{p}=0.067)$ & $\mathrm{n} / \mathrm{a}$ & $0.24 * *$ & $-0.27^{* *}$ & $-0.19(\mathrm{p}=0.055)$ \\
\hline Gender & $\mathrm{n} / \mathrm{a}$ & $-0.36^{* *}$ & $\mathrm{n} / \mathrm{a}$ & $\mathrm{n} / \mathrm{a}$ & $\mathrm{n} / \mathrm{a}$ & $\mathrm{n} / \mathrm{a}$ \\
\hline Age & $\mathrm{n} / \mathrm{a}$ & $\mathrm{n} / \mathrm{a}$ & $0.27^{*}$ & $\mathrm{n} / \mathrm{a}$ & $\mathrm{n} / \mathrm{a}$ & $\mathrm{n} / \mathrm{a}$ \\
\hline NYE & $\mathrm{n} / \mathrm{a}$ & $-0.26(\mathrm{p}=0.59)$ & $\mathrm{n} / \mathrm{a}$ & $\mathrm{n} / \mathrm{a}$ & $\mathrm{n} / \mathrm{a}$ & $\mathrm{n} / \mathrm{a}$ \\
\hline MMSE score & $\mathrm{n} / \mathrm{a}$ & $\mathrm{n} / \mathrm{a}$ & $\mathrm{n} / \mathrm{a}$ & $0.17(\mathrm{p}=0.061)$ & -0.19 & $-0.26^{* *}$ \\
\hline Presence of the ApoE\&4 allele & $-0.29^{*}$ & $\mathrm{n} / \mathrm{a}$ & $-0.26(\mathrm{p}=0.058)$ & $-0.39^{* * *}$ & $0.20^{*}$ & $0.23^{*}$ \\
\hline
\end{tabular}

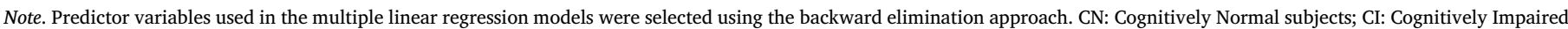

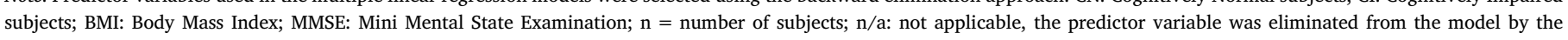
backward elimination approach; n.s.: nonsignificant; NYE: number of years of education.

${ }^{*} \mathrm{p} \leq 0.05$.
${ }^{* *} \mathrm{p} \leq 0.01$.
${ }^{* * *} \mathrm{p} \leq 0.00$. 


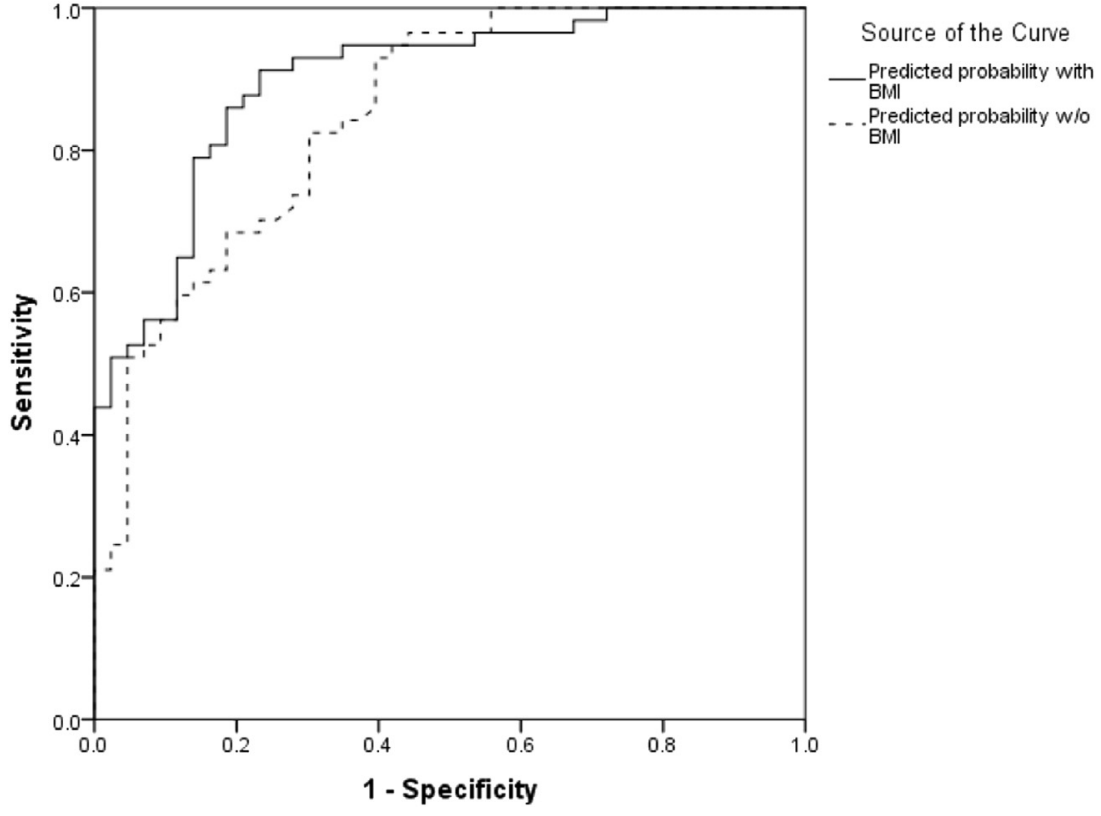

Fig. 4. ROC curve showing the predictive power of a model integrating age, gender, number of education years, Mini Mental State Examination score and ApoE\&4 with and without Body Mass Index in order to predict pathological CSF AD biomarker profile in the subjects with cognitive impairment. including different clinical types of MCI suggest that amyloid pathology, neuronal injury, and tau hyperphorsphorylation as measured by CSF biomarkers are associated with low BMI. These associations become evident at the pre-dementia clinical stage of $\mathrm{AD}$ and seem to be independent of the severity of cognitive impairment. Moreover, we found that tau and P-tau levels at inclusion were related to decreasing BMI over a follow-up time of 18 months suggesting a close and specific relationship between cerebral tau-related neurodegeneration and weight loss.

Memory clinic patients presenting MCI and mild dementia are a very heterogeneous group regarding the underlying pathology (Winblad et al., 2004). Only a part of these subjects have cerebral AD pathology as the main cause of cognitive impairment. Differentiating MCI due to $\mathrm{AD}$ from MCI due to other conditions may have major consequences for clinical decision making, especially regarding further, individually chosen diagnostic tests or a "watchful waiting" attitude and clinical follow-up, and early and specific treatment options (Popp and Arlt, 2011). Biomarkers of AD pathology are not always available, or their use may be limited by contraindications, patient refusal, and costs. Therefore, it remains important to identify clinical factors that improve the accuracy of the $\mathrm{AD}$ diagnosis. Despite being an easily available and low-cost measure, BMI, or change in BMI over time, is not yet integrated in the clinician's rationale as an indicator of $\mathrm{AD}$ pathology in patients with cognitive complaints or beginning decline. To our knowledge, this is the first study that evaluated the potential of BMI to improve, together with other clinical factors, the diagnostic accuracy of AD. Adding BMI to a model including demographic and clinical factors substantially improved sensitivity and specificity of the model to predict the presence of $\mathrm{AD}$ pathology in memory clinic patients with MCI or mild dementia. The results suggest that BMI could be considered along with other relevant clinical parameters to evaluate the individual risk of the presence of cerebral AD pathology in patients with cognitive impairment, in particular if biomarkers are not easily available.

Analysis using longitudinal follow-up data available in a subgroup of the study participants showed a correlation between decreasing BMI and MMSE score decline. While preliminary, this additional finding are in line with a recent study showing that in patients with MCI lower BMI predicts evolution to dementia (Cova et al., 2016), and suggests that decreasing BMI may not only be a clinical indicator of cerebral pathology, but also a clinical factor that could help to identify patients at risk for rapid cognitive decline.
The current study has limitations. As a measure of the nutritional status, BMI was shown to have equal or superior performance compared to other body fat-measuring methods (Smith et al., 2014). More precise assessment of changes in body composition may provide additional and more specific information, however (Buffa et al., 2014; Cova et al., 2017). Furthermore, the CN group was too small to appropriately address the question of whether the observed associations between BMI and AD CSF biomarkers may precede the clinical stage of the disease. While preliminary analysis in a subset of subjects with follow-up data indicates that cerebral tau pathology is associated with decreasing BMI over time, further prospective investigation in a larger sample is needed to understand the dynamics between weight loss and cerebral pathology.

\section{Conclusions}

While the precise mechanisms underlying the association between weight loss, metabolic changes, and $\mathrm{AD}$ remain to be unraveled, our study provide new evidence suggesting that low and decreasing BMI is associated with CSF biomarkers of cerebral AD pathology in memory clinic patients with MCI or mild dementia. When considered together with other clinical features, decreasing BMI may contribute to improve the diagnosis of $\mathrm{AD}$ at early clinical stages, and may indicate higher risk of rapid cognitive decline.

\section{Funding}

This work was supported by the Swiss National Science Foundation, grant: 320030L_141179.

\section{Declaration of interest}

None of the authors have any conflicts of interest to disclose.

\section{Acknowledgments}

The authors thankfully acknowledge the volunteers and patients enrolled in our study. The authors would also like to thank Aikaterini Oikonomidi, MD, Barbara Moullet, Catherine Montero Lamelas, Quentin Delval, and Rebecca Savioz for their assistance and helpful comments on the manuscript. 


\section{References}

Albanese, E., Taylor, C., Siervo, M., Stewart, R., Prince, M.J., Acosta, D., 2013. Dementia severity and weight loss: a comparison across eight cohorts. The 10/66 study. Alzheimers Dement. 9, 649-656.

Albert, M.S., DeKosky, S.T., Dickson, D., Dubois, B., Feldman, H.H., Fox, N.C., Gamst, A., Holtzman, D.M., Jagust, W.J., Petersen, R.C., Snyder, P.J., Carrillo, M.C., Thies, B., Phelps, C.H., 2011. The diagnosis of mild cognitive impairment due to Alzheimer's disease: recommendations from the National Institute on Aging-Alzheimer's Association workgroups on diagnostic guidelines for Alzheimer's disease. Alzheimers Dement. 7, 270-279.

Beach, T.G., Monsell, S.E., Phillips, L.E., Kukull, W., 2012. Accuracy of the clinical diagnosis of Alzheimer disease at National Institute on Aging Alzheimer Disease Centers, 2005-2010. J. Neuropathol. Exp. Neurol. 71, 266-273.

Buchman, A.S., Schneider, J.A., Wilson, R.S., Bienias, J.L., Bennett, D.A., 2006. Body mass index in older persons is associated with Alzheimer disease pathology. Neurology 67, 1949-1954.

Buffa, R., Mereu, E., Putzu, P., Mereu, R.M., Marini, E., 2014. Lower lean mass and higher percent fat mass in patients with Alzheimer's disease. Exp. Gerontol. 58, 30-33.

Buschke, H., Sliwinski, M.J., Kuslansky, G., Lipton, R.B., 1997. Diagnosis of early dementia by the Double Memory Test: encoding specificity improves diagnostic sensitivity and specificity. Neurology 48, 989-997.

Cardebat, D., Doyon, B., Puel, M., Goulet, P., Joanette, Y., 1990. Formal and semantic lexical evocation in normal subjects. Performance and dynamics of production as a function of sex, age and educational level. Acta Neurol. Belg. 90, 207-217.

Chung, K.S., Lee, J.K., Park, J.S., Choi, C.H., 2015. Risk factors of delirium in patients undergoing total knee arthroplasty. Arch. Gerontol. Geriatr. 60, 443-447.

Cova, I., Clerici, F., Maggiore, L., Pomati, S., Cucumo, V., Ghiretti, R., Galimberti, D., Scarpini, E., Mariani, C., Caracciolo, B., 2016. Body mass index predicts progression of mild cognitive impairment to dementia. Dement. Geriatr. Cogn. Disord. 41, $172-180$.

Cova, I., Pomati, S., Maggiore, L., Forcella, M., Cucumo, V., Ghiretti, R., Grande, G., Muzio, F., Mariani, C., 2017. Nutritional status and body composition by bioelectrical impedance vector analysis: a cross sectional study in mild cognitive impairment and Alzheimer's disease. PLoS One 12, e0171331.

Deschamps, V., Astier, X., Ferry, M., Rainfray, M., Emeriau, J.P., Barberger-Gateau, P., 2002. Nutritional status of healthy elderly persons living in Dordogne, France, and relation with mortality and cognitive or functional decline. Eur. J. Clin. Nutr. 56, 305-312.

Donovan, N.J., Amariglio, R.E., Zoller, A.S., Rudel, R.K., Gomez-Isla, T., Blacker, D., Hyman, B.T., Locascio, J.J., Johnson, K.A., Sperling, R.A., Marshall, G.A., Rentz, D.M., 2014. Subjective cognitive concerns and neuropsychiatric predictors of progression to the early clinical stages of Alzheimer's disease. Am. J. Geriatr. Psychiatry $22,1642-1651$

Duara, R., Loewenstein, D.A., Potter, E., Appel, J., Greig, M.T., Urs, R., Shen, Q., Raj, A., Small, B., Barker, W., Schofield, E., Wu, Y., Potter, H., 2008. Medial temporal lobe atrophy on MRI scans and the diagnosis of Alzheimer disease. Neurology 71, 1986-1992.

Duits, F.H., Teunissen, C.E., Bouwman, F.H., Visser, P.J., Mattsson, N., Zetterberg, H., Blennow, K., Hansson, O., Minthon, L., Andreasen, N., Marcusson, J., Wallin, A., Rikkert, M.O., Tsolaki, M., Parnetti, L., Herukka, S.K., Hampel, H., De Leon, M.J., Schroder, J., Aarsland, D., Blankenstein, M.A., Scheltens, P., van der Flier, W.M., 2014. The cerebrospinal fluid "Alzheimer profile": easily said, but what does it mean? Alzheimers Dement. 10, 713-723 (e712).

Erol, A., 2008. An integrated and unifying hypothesis for the metabolic basis of sporadic Alzheimer's disease. J. Alzheimers Dis. 13, 241-253.

Ewers, M., Schmitz, S., Hansson, O., Walsh, C., Fitzpatrick, A., Bennett, D., Minthon, L., Trojanowski, J.Q., Shaw, L.M., Faluyi, Y.O., Vellas, B., Dubois, B., Blennow, K., Buerger, K., Teipel, S.J., Weiner, M., Hampel, H., 2012. Alzheimer's disease neuroimaging, I. Body mass index is associated with biological CSF markers of core brain pathology of Alzheimer's disease. Neurobiol. Aging 33, 1599-1608.

Fitzpatrick, A.L., Kuller, L.H., Lopez, O.L., Diehr, P., O'Meara, E.S., Longstreth Jr., W.T., Luchsinger, J.A., 2009. Midlife and late-life obesity and the risk of dementia: cardiovascular health study. Arch. Neurol. 66, 336-342.

Geda, Y.E., Roberts, R.O., Mielke, M.M., Knopman, D.S., Christianson, T.J., Pankratz, V.S., Boeve, B.F., Sochor, O., Tangalos, E.G., Petersen, R.C., Rocca, W.A., 2014. Baseline neuropsychiatric symptoms and the risk of incident mild cognitive impairment: a population-based study. Am. J. Psychiatry 171, 572-581.

González-Domínguez, R., García-Barrera, T., Gómez-Ariza, J.L., 2015. Metabolite profiling for the identification of altered metabolic pathways in Alzheimer's disease. J. Pharm. Biomed. Anal. 107, 75-81.

Grundman, M., Corey-Bloom, J., Jernigan, T., Archibald, S., Thal, L.J., 1996. Low body weight in Alzheimer's disease is associated with mesial temporal cortex atrophy. Neurology 46, 1585-1591.

Heneka, M.T., Carson, M.J., Khoury, J.E., Landreth, G.E., Brosseron, F., Feinstein, D.L., Jacobs, A.H., Wyss-Coray, T., Vitorica, J., Ransohoff, R.M., Herrup, K., Frautschy, S.A., Finsen, B., Brown, G.C., Verkhratsky, A., Yamanaka, K., Koistinaho, J., Latz, E., Halle, A., Petzold, G.C., Town, T., Morgan, D., Shinohara, M.L., Perry, V.H., Holmes, C., Bazan, N.G., Brooks, D.J., Hunot, S., Joseph, B., Deigendesch, N., Garaschuk, O., Boddeke, E., Dinarello, C.A., Breitner, J.C., Cole, G.M., Golenbock, D.T., Kummer, M.P., 2015. Neuroinflammation in Alzheimer's disease. Lancet Neurol. 14, 388-405.

Hsu, D.C., Mormino, E.C., Schultz, A.P., Amariglio, R.E., Donovan, N.J., Rentz, D.M., Johnson, K.A., Sperling, R.A., Marshall, G.A., 2016. Lower late-life body-mass index is associated with higher cortical amyloid burden in clinically normal elderly. J. Alzheimers Dis. 53, 1097-1105.
Ishii, M., Iadecola, C., 2015. Metabolic and non-cognitive manifestations of Alzheimer's disease: the hypothalamus as both culprit and target of pathology. Cell Metab. 22, 761-776.

Jansen, W.J., Ossenkoppele, R., Knol, D.L., Tijms, B.M., Scheltens, P., Verhey, F.R., Visser, P.J., Aalten, P., Aarsland, D., Alcolea, D., Alexander, M., Almdahl, I.S., Arnold, S.E., Baldeiras, I., Barthel, H., van Berckel, B.N., Bibeau, K., Blennow, K., Brooks, D.J., van Buchem, M.A., Camus, V., Cavedo, E., Chen, K., Chetelat, G., Cohen, A.D., Drzezga, A., Engelborghs, S., Fagan, A.M., Fladby, T., Fleisher, A.S., van der Flier, W.M., Ford, L., Forster, S., Fortea, J., Foskett, N., Frederiksen, K.S., Freund-Levi, Y., Frisoni, G.B., Froelich, L., Gabryelewicz, T., Gill, K.D., Gkatzima, O., Gomez-Tortosa, E., Gordon, M.F., Grimmer, T., Hampel, H., Hausner, L., Hellwig, S., Herukka, S.K., Hildebrandt, H., Ishihara, L., Ivanoiu, A., Jagust, W.J., Johannsen, P., Kandimalla, R., Kapaki, E., Klimkowicz-Mrowiec, A., Klunk, W.E., Kohler, S., Koglin, N., Kornhuber, J., Kramberger, M.G., Van Laere, K., Landau, S.M., Lee, D.Y., de Leon, M., Lisetti, V., Lleo, A., Madsen, K., Maier, W., Marcusson, J., Mattsson, N., de Mendonca, A., Meulenbroek, O., Meyer, P.T., Mintun, M.A., Mok, V., Molinuevo, J.L., Mollergard, H.M., Morris, J.C., Mroczko, B., Van der Mussele, S., Na, D.L., Newberg, A., Nordberg, A., Nordlund, A., Novak, G.P., Paraskevas, G.P., Parnetti, L., Perera, G., Peters, O., Popp, J., Prabhakar, S., Rabinovici, G.D., Ramakers, I.H., Rami, L., Resende de Oliveira, C., Rinne, J.O., Rodrigue, K.M., Rodriguez-Rodriguez, E., Roe, C.M., Rot, U., Rowe, C.C., Ruther, E., Sabri, O., Sanchez-Juan, P., Santana, I., Sarazin, M., Schroder, J., Schutte, C., Seo, S.W., Soetewey, F., Soininen, H., Spiru, L., Struyfs, H., Teunissen, C.E., Tsolaki, M., Vandenberghe, R., Verbeek, M.M., Villemagne, V.L., Vos, S.J., van Waalwijk van Doorn, L.J., Waldemar, G., Wallin, A., Wallin, A.K., Wiltfang, J., Wolk, D.A., Zboch, M., Zetterberg, H., 2015. Prevalence of cerebral amyloid pathology in persons without dementia: a meta-analysis. JAMA 313, 1924-1938.

Johnson, D.K., Wilkins, C.H., Morris, J.C., 2006. Accelerated weight loss may precede diagnosis in Alzheimer disease. Arch. Neurol. 63, 1312-1317.

Juliebo, V., Bjoro, K., Krogseth, M., Skovlund, E., Ranhoff, A.H., Wyller, T.B., 2009. Risk factors for preoperative and postoperative delirium in elderly patients with hip fracture. J. Am. Geriatr. Soc. 57, 1354-1361.

Knopman, D.S., Edland, S.D., Cha, R.H., Petersen, R.C., Rocca, W.A., 2007. Incident dementia in women is preceded by weight loss by at least a decade. Neurology 69, 739-746.

Lawton, M.P., Brody, E.M., 1969. Assessment of older people: self-maintaining and instrumental activities of daily living. The Gerontologist 9, 179-186.

Luchsinger, J.A., Patel, B., Tang, M.X., Schupf, N., Mayeux, R., 2008. Body mass index, dementia, and mortality in the elderly. J. Nutr. Health Aging 12, 127-131.

Marino, L.V., Ramos, L.F., Chiarello, P.G., 2015. Nutritional status according to the stages of Alzheimer's disease. Aging Clin. Exp. Res. 27, 507-513.

McKhann, G.M., Knopman, D.S., Chertkow, H., Hyman, B.T., Jack Jr., C.R., Kawas, C.H., Klunk, W.E., Koroshetz, W.J., Manly, J.J., Mayeux, R., Mohs, R.C., Morris, J.C., Rossor, M.N., Scheltens, P., Carrillo, M.C., Thies, B., Weintraub, S., Phelps, C.H., 2011. The diagnosis of dementia due to Alzheimer's disease: recommendations from the National Institute on Aging-Alzheimer's Association workgroups on diagnostic guidelines for Alzheimer's disease. Alzheimers Dement. 7, 263-269.

Merrill, D.A., Siddarth, P., Raji, C.A., Emerson, N.D., Rueda, F., Ercoli, L.M., Miller, K.J., Lavretsky, H., Harris, L.M., Burggren, A.C., Bookheimer, S.Y., Barrio, J.R., Small, G.W., 2016. Modifiable risk factors and brain positron emission tomography measures of amyloid and tau in nondemented adults with memory complaints. Am. J. Geriatr. Psychiatry 24, 729-737.

Molinuevo, J.L., Blennow, K., Dubois, B., Engelborghs, S., Lewczuk, P., Perret-Liaudet, A., Teunissen, C.E., Parnetti, L., 2014. The clinical use of cerebrospinal fluid biomarker testing for Alzheimer's disease diagnosis: a consensus paper from the Alzheimer's Biomarkers Standardization Initiative. Alzheimers Dement. 10, 808-817.

Morris, J.C., 1993. The Clinical Dementia Rating (CDR): current version and scoring rules. Neurology 43, 2412-2414.

Musiek, E.S., Holtzman, D.M., 2015. Three dimensions of the amyloid hypothesis: time, space and 'wingmen'. Nat. Neurosci. 18, 800-806.

Oh, E.S., Li, M., Fafowora, T.M., Inouye, S.K., Chen, C.H., Rosman, L.M., Lyketsos, C.G., Sieber, F.E., Puhan, M.A., 2015. Preoperative risk factors for postoperative delirium following hip fracture repair: a systematic review. Int. J. Geriatr. Psychiatry 30 900-910.

Popp, J., 2013. Delirium and cognitive decline: more than a coincidence. Curr. Opin. Neurol. 26, 634-639.

Popp, J., Arlt, S., 2011. Pharmacological treatment of dementia and mild cognitive impairment due to Alzheimer's disease. Curr. Opin. Psychiatry 24, 556-561.

Popp, J., Riad, M., Freymann, K., Jessen, F., 2007. Diagnostic lumbar puncture performed in the outpatient setting of a memory clinic. Frequency and risk factors of postlumbar puncture headache. Nervenarzt 78, 547-551.

Popp, J., Lewczuk, P., Frommann, I., Kolsch, H., Kornhuber, J., Maier, W., Jessen, F., 2010. Cerebrospinal fluid markers for Alzheimer's disease over the lifespan: effects of age and the APOEepsilon4 genotype. J. Alzheimers Dis. 22, 459-468.

Popp, J., Oikonomidi, A., Tautvydaite, D., Dayon, L., Bacher, M., Migliavacca, E., Henry, H., Kirkland, R., Severin, I., Wojcik, J., Bowman, G.L., 2017. Markers of neuroinflammation associated with Alzheimer's disease pathology in older adults. Brain Behav. Immun.

Prince, M., Bryce, R., Albanese, E., Wimo, A., Ribeiro, W., Ferri, C.P., 2013. The global prevalence of dementia: a systematic review and metaanalysis. Alzheimers Dement. 9, 63-75.

Reitan, R.M., 1958. Validity of the Trail Making Test as an indicator of organic brain damage. Percept. Mot. Skills 8, 271-276.

Sato, N., Morishita, R., 2015. The roles of lipid and glucose metabolism in modulation of $\beta$-amyloid, tau, and neurodegeneration in the pathogenesis of Alzheimer disease. Front. Aging Neurosci. 7, 199.

Scheltens, P., Blennow, K., Breteler, M.M., de Strooper, B., Frisoni, G.B., Salloway, S., Van 
der Flier, W.M., 2016. Alzheimer's disease. Lancet 388, 505-517.

Smith, E., Bailey, P.E., Crawford, J., Samaras, K., Baune, B.T., Campbell, L., Kochan, N., Menant, J., Sturnieks, D.L., Brodaty, H., Sachdev, P., Trollor, J.N., 2014. Adiposity estimated using dual energy X-ray absorptiometry and body mass index and its association with cognition in elderly adults. J. Am. Geriatr. Soc. 62, 2311-2318.

Soto, M.E., Secher, M., Gillette-Guyonnet, S., Abellan van Kan, G., Andrieu, S.,

Nourhashemi, F., Rolland, Y., Vellas, B., 2012. Weight loss and rapid cognitive decline in community-dwelling patients with Alzheimer's disease. J. Alzheimers Dis. 28, 647-654.

Stroop, J.R., 1935. Studies of interference in serial verbal reactions. J. Exp. Psychol. 18, 643-662.

Tautvydaite, D., Kukreja, D., Antonietti, J.P., Henry, H., von Gunten, A., Popp, J., 2017. Interaction between personality traits and cerebrospinal fluid biomarkers of Alzheimer's disease pathology modulates cognitive performance. Alzheimers Res. Ther. 9, 6 .

Val-Laillet, D., Aarts, E., Weber, B., Ferrari, M., Quaresima, V., Stoeckel, L.E., AlonsoAlonso, M., Audette, M., Malbert, C.H., Stice, E., 2015. Neuroimaging and neuromodulation approaches to study eating behavior and prevent and treat eating disorders and obesity. NeuroImage 8, 1-31.

Vidoni, E.D., Townley, R.A., Honea, R.A., Burns, J.M., 2011. Alzheimer's Disease

Neuroimaging, I. Alzheimer disease biomarkers are associated with body mass index. Neurology 77, 1913-1920.

Wechsler, D.A., 1955. Manual for the Wechsler Adult Intelligence Scale. Psychological Corporation, New York.

White, H., Pieper, C., Schmader, K., Fillenbaum, G., 1996. Weight change in Alzheimer's disease. J. Am. Geriatr. Soc. 44, 265-272.

Winblad, B., Palmer, K., Kivipelto, M., Jelic, V., Fratiglioni, L., Wahlund, L.O., Nordberg, A., Backman, L., Albert, M., Almkvist, O., Arai, H., Basun, H., Blennow, K., de Leon, M., DeCarli, C., Erkinjuntti, T., Giacobini, E., Graff, C., Hardy, J., Jack, C., Jorm, A., Ritchie, K., van Duijn, C., Visser, P., Petersen, R.C., 2004. Mild cognitive impairment-beyond controversies, towards a consensus: report of the International Working Group on Mild Cognitive Impairment. J. Intern. Med. 256, 240-246.

Zigmond, A.S., Snaith, R.P., 1983. The hospital anxiety and depression scale. Acta Psychiatr. Scand. 67, 361-370. 